\title{
Researches regarding the Applications of Permanent Magnet Motors for Vehicle Propulsion
}

\author{
BOLFA TRAIAN EUGEN \\ Department of Strength of Materials \\ Transylvania University of Brasov \\ B-dul Eroilor 29, 500036 Brasov \\ ROMANIA
}

\begin{abstract}
In this paper the author presents a laboratory bench used to test Permanent Magnet (PM) motors for vehicle propulsion. The general schemas for the bench, the PM motor types tested, the traction characteristics and some experimental results are evaluated. These techniques are appropriate for teaching students in practical laboratory applications regarding electrical and hybrid vehicles. Students are able to improve their practical skills and also to develop research projects jointly with the teaching staff.
\end{abstract}

Key-Words: Power Systems, Applications, hybrid vehicles, permanent magnets

Received: December 22, 2019. Revised: May 31, 2020, Re-revised: June 11, 2020. Accepted: June 15, 2020. Published: June 17, 2020

\section{Introduction}

During the recent years, within large urban areas, many developments have taken place with Electric Vehicles (EV) and Hybrid Electric Vehicles (HEV) to provide environmentally beneficial solutions for the transport of both passengers and goods. In recent estimations, in the next twenty years, within large urban areas, car density will increase substantially.

This will further increase the pressure on fuel prices and will cause serious problems to the environment (pollution and green house effect). Some major requirements need to be achieved by passengers and goods vehicles, as follows:

- have large autonomy;

- have short refueling time;

- provide acceleration of between10 to $15 \mathrm{~s}$ from stationary to $100 \mathrm{~km} / \mathrm{h}$;

- can be driven uphill on 5-10\% ramps at the legal top speed;

- be safe and cause no environmental hazards.

In this case, is very important to have a good selection of an appropriate traction motor for the vehicle propulsion system. Within research projects, in Transylvania University of Brasov, Romania, there has beendeveloped some practical applications for testing PM motors for vehicle propulsion.

\section{Traction Characteristics}

From the traction characteristics it is possible to make an evaluation of the dynamic, economic and other vehicle indices being determined by calculation (the theoretical characteristic), or by practical testing.

To have good dynamics and respecting the vehicle's operating constraints, it requires an extended speed range and a constant power operating flexible region for different hill climbing conditions. To obtain a complete estimation of traction characteristics, it is necessary to calculate the dependence between the vehicle power $\left(P_{v}\right)$ and its speed $(v)$ within the traffic, as follows:

$$
P_{v}=\left(m_{v} \cdot g \cdot C_{r}+\frac{\rho_{a} \cdot A_{f} \cdot C_{d}}{2} \cdot v^{2}\right) \cdot v,
$$

where: $m_{v}$ is the loaded vehicle mass, $g$ is the gravity acceleration, $\mathrm{Cr}$ is the wheel rolling coefficient, $v$ is the vehicle speed, $\rho_{a}$ is the air density, $A_{f}$ is the vehicle frontal area and $C_{d}$ is the aerodynamic drag coefficient usually estimated by experiments or using computer programs.

The power characteristic presents also two regions: linearly power increasing until the base speed (30 $\mathrm{km} / \mathrm{h}$ ) - known also as constant torque region and the constant power region between the base speed and the maximum extended one. The extended speed 
ratio $\left(v_{\text {max }} / v_{\text {base }}\right)$ is almost independent of the vehicle mass, because the aerodynamic drag is not weight depending and has less impact on the extended speed ratio than the tire friction which linearly depends on the weight $[2,3]$.

Taking into account the equation (1) and the numerical values of the traction powers for different vehicle classes [2, 4], in Fig.1 are depicted the traction characteristics for some vehicle classes driven by PM electrical traction motors.

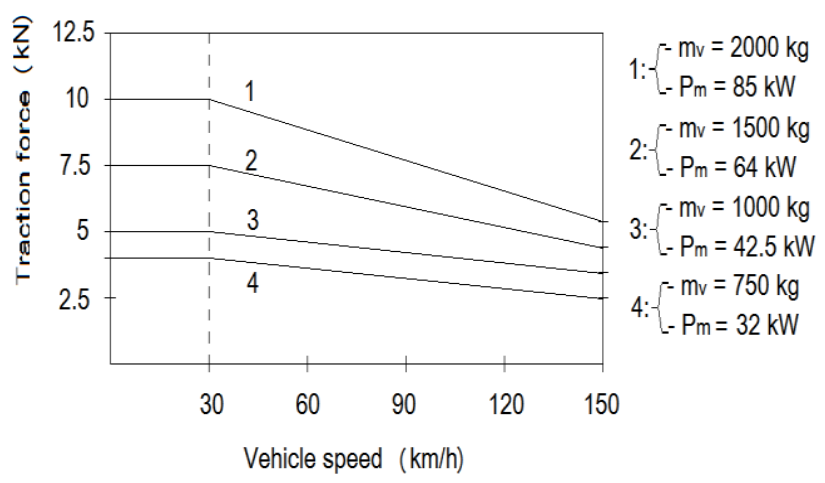

Fig.1Traction characteristics

\section{Permanent magnet motors testing}

The general schematic of the test bench where the PM motors have been tested is presented in Fig.2.

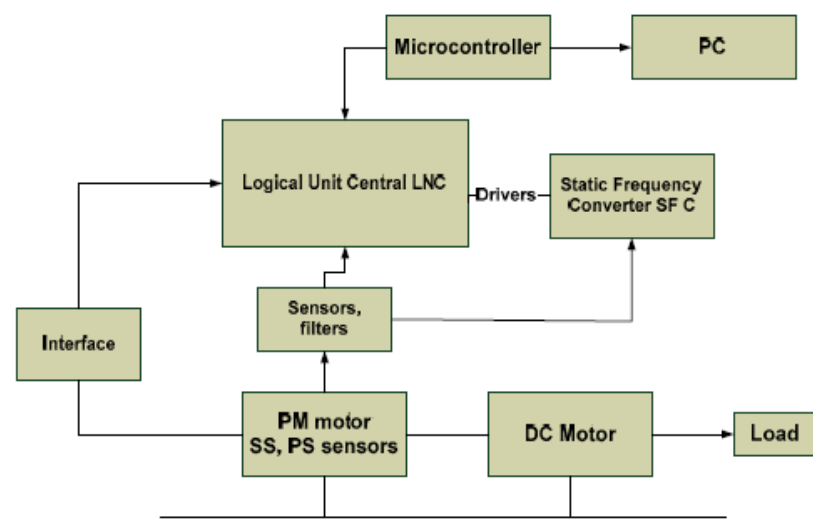

Fig.2 General diagram of the test bench

To obtain the experimental PM motor model measurements the testing bench presented in Fig.3 has been used.

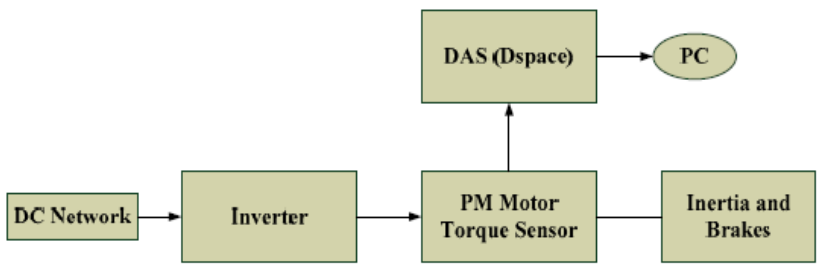

Fig.3 Testing bench for motor measurements Two types of traction PM motors are proposed and their models are developed, using experimental tests and data processing.

The main traction characteristics are obtained for the followings PM motors:

a) brushless motor type NX840, with the main rated parameters: $V_{n}=230 \mathrm{~V}, I_{n}=42.9 \mathrm{~A}, T==35 \mathrm{Nm}, n$ $=3300 \mathrm{rpm}, P=12 \mathrm{~kW}$.

The motor has been presented in paper [6], with a complete analysis. It is equipped with a torque sensor to directly measure the torque to the motor shaft. The measurement system contains three outputs and of these analog/digital output values for torque and speed are readable. The output signal for the torque is voltage $V_{\text {out }}=0 \ldots 10 \mathrm{~V}$ or current $I_{\text {out }}=$ 4...20mA. The voltage across the inverter, coming from the $\mathrm{DC}$ bus, is acquired by voltage sensors type LV100-100. Current measurements of DC bus have been obtained through current sensors type LEM LA 205-S. Brakes develop a resistant torque with a manually adjustable value by adjusting the field current. Inertia, type VI100B, $1.5 \mathrm{~kW}$ power, permits the permanent rotation quite safely at $8000 \mathrm{rpm}$. Inertia and brakes represent the mechanical load of the vehicle powered by the PM motor. The data acquisition system (DAS) is provided by the DSpace real-time-board. Tests are performed within load operating, the inertia and brake being coupled gradually, in a dynamic way.

b) synchronous motor type ST142-2/6 M, having the following data: rated voltage $196 \mathrm{~V}$, rated current 9.3 $A$, maximum rotation speed $6000 \mathrm{rpm}$, rated/maximum torque $2.2 / 2.9 \mathrm{~N} / \mathrm{m}$, pole pair number 3. The motor is equipped with two sensors: - rotor speed sensor (RSS) with output signal of 1.6 $m V / r o t ;$

- position sensor (PS) with three Hall probes placed at 120 degrees.

The DC machine representing the load of PM motor is of CD 42 UV type. In Table 1, the data sheets of the DC machine are given.

Table 1. Data sheets of the DC machine

\begin{tabular}{|l|l|l|}
\hline Parameter & Symbol & Value \\
\hline Power, $\mathrm{kW}$ & $\mathrm{P}$ & 2.2 \\
\hline Rotor speed, rpm & $\mathrm{n}_{\max }$ & 3000 \\
\hline Armature voltage, $\mathrm{V}$ & $\mathrm{V}$ & 275 \\
\hline Current, A & $\mathrm{I}$ & 12.5 \\
\hline
\end{tabular}

Using this load, traction typical operating modes are realized: constant torque, constant power and dynamical breaking (through rheostats).

The static frequency converter is composed by a 
bidirectional three-phase rectifier and three-phase VSI inverter, with a maximum power of $30 \mathrm{kVA}$, voltage of $200 \mathrm{~V}$ and current of $15 \mathrm{~A}$ at a frequency of $1000 \mathrm{~Hz}$.

In order to reduce the current harmonics and to decrease its amplitude, a control PWM strategy to the supply voltage between $(+0.5 \mathrm{~V}, 0)$ and $(0,-0.5$ $V$ ) has been used.

The logic control unit (LCN) provides an independent control of the PM stator voltage and of frequency so that their ratio is constant $(\mathrm{V} / \mathrm{f}=$ const.).

\section{Experimental results}

To obtain accurate results, precise experimental models of PM synchronous motor drives, were acquired with the DSpace system.

The stage of data processing has been done assisted by Matlab Simulink software.

In simulations, measured values as rotation speed $n$ and mechanical power $P_{\mathrm{m}}$ have been introduced as input data, in order to obtain the output of electrical power $P_{\mathrm{e}}$ required by the motor to work in the specified traction operating modes.

The Simulink schematic that leads to the experimental model of PM motor is presented in Fig. 4.

Then, using netlablibrary from Matlab that allows working with neural network and motor data acquired, several types of graphshave been obtained. For the PM motor type ST142-2/6 M it has been established the rated regime, characterized by measured and computed data, presented in Table 2 and Table 3.

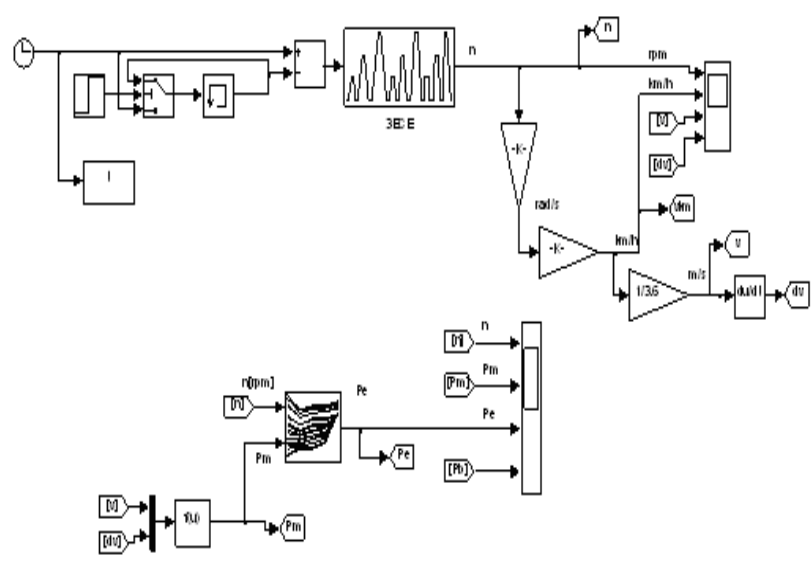

Fig.4 Simulink schema for experimental model of the PM motor
Table 2 Rated measured data of PM motor

\begin{tabular}{|l|l|l|}
\hline Parameter & Symbol & Value \\
\hline Torque, $\mathrm{Nm}$ & $\mathrm{T}_{\mathrm{n}}\left(\mathrm{C}_{\mathrm{n}}\right)$ & 2.85 \\
\hline Power, $\mathrm{W}$ & $\mathrm{P}_{\mathrm{n}}$ & 900 \\
\hline Frequency, $\mathrm{Hz}$ & $\mathrm{f}_{\mathrm{n}}$ & 152 \\
\hline Phase voltage, $\mathrm{V}$ & $\mathrm{U}_{\mathrm{fn}}$ & 50 \\
\hline Phase current, $\mathrm{A}$ & $\mathrm{I}_{\mathrm{fn}}$ & 8.5 \\
\hline Rotor speed, $\mathrm{rpm}$ & $\mathrm{n}_{\mathrm{n}}$ & 3000 \\
\hline Power factor & $\cos \varphi_{\mathrm{n}}$ & 0.998 \\
\hline
\end{tabular}

Table 3Rated computed data of PM motor

\begin{tabular}{|l|l|l|}
\hline Parameter & Symbol & Value \\
\hline Power, $\mathrm{W}$ & $\mathrm{P}_{\mathrm{n}}$ & 895.35 \\
\hline Frequency, $\mathrm{Hz}$ & $\mathrm{f}_{\mathrm{n}}$ & 150 \\
\hline Rotor speed, rpm & $\mathrm{n}_{\mathrm{n}}$ & 3000 \\
\hline Phase voltage, $\mathrm{V}$ & $\mathrm{U}_{\mathrm{fn}}$ & 48.1 \\
\hline
\end{tabular}

The rated operating mode of PM motor has been established so that the PM motor is not overloaded and a power reserve is achieved: $\quad I_{n}<I_{\max }=9.3 \mathrm{~A}$ and $T_{n}<T_{\max }=2.9 \mathrm{Nm}$.

Once the operating mode has been defined and using the data acquisition system, the following parameters, presented in Table 4 for the PM motor, have been determined.

Table 4Measured parameters of PM motor

\begin{tabular}{|l|l|l|}
\hline Parameter & Symbol & Value \\
\hline $\begin{array}{l}\text { Relative permeability of } \\
\mathrm{PM}(\text { Nd-B-Fe) }\end{array}$ & $\mu_{\mathrm{r}}$ & 1.05 \\
\hline $\begin{array}{l}\text { Remanent magnetic induc- } \\
\text { tion, } \mathrm{T}\end{array}$ & $\mathrm{B}_{\mathrm{t}}$ & 1.25 \\
\hline $\begin{array}{l}\text { Permanent magnet resis- } \\
\text { tivity, } \Omega \mathrm{cm}\end{array}$ & $\rho_{\mathrm{PM}}$ & $15 \cdot 10^{5}$ \\
\hline $\begin{array}{l}\text { Stator winding resistance, } \\
\mathrm{m} \Omega\end{array}$ & $\mathrm{R}_{\mathrm{s}}$ & 1.7 \\
\hline Synchronous reactance, $\mathrm{m} \Omega$ & $\mathrm{X}_{\mathrm{s}}=X_{\mathrm{d}}$ & 30 \\
\hline Rated power factor & $\cos \varphi_{\mathrm{n}}$ & 0.998 \\
\hline $\begin{array}{l}\text { Proper flow of permanent } \\
\text { magnet, Wb }\end{array}$ & $\psi_{\mathrm{pr}}$ & 0.0745 \\
\hline
\end{tabular}

According to the rated operating modes experimentally defined, the constant torque and the constant power regions have been analyzed.

Constant torque curves are presented in Fig. 5 and they have been plotted for three values of the field current of the dc motor (as load):

- curve $1 I_{e l}=0.21 \mathrm{~A}$ - rated mode,

- curve $2 I_{e 2}=0.71 I_{e l}$,

- curve $3 I_{e 3}=0.51 I_{e 2}$. 


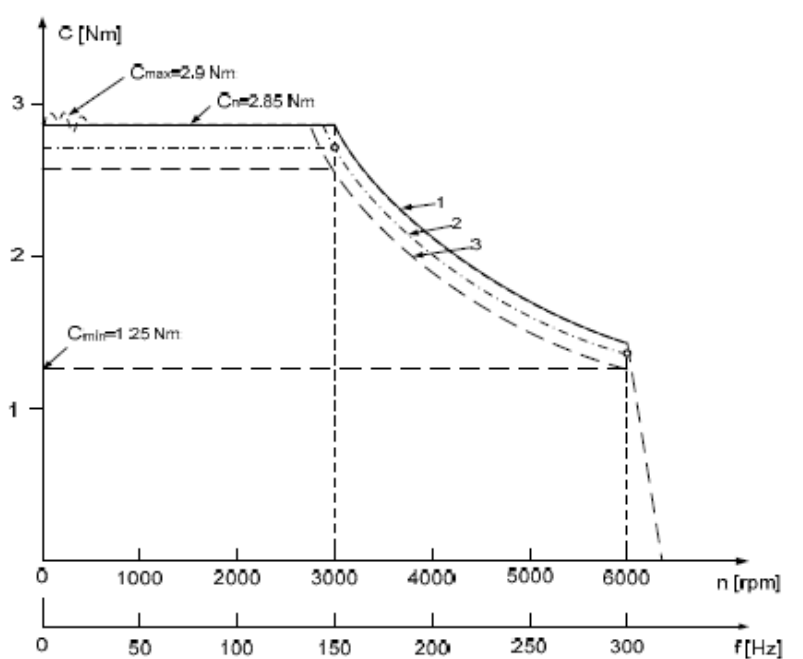

Fig.5 Experimental torque curves of PM motor

In Fig.6 constant power curves are shown.

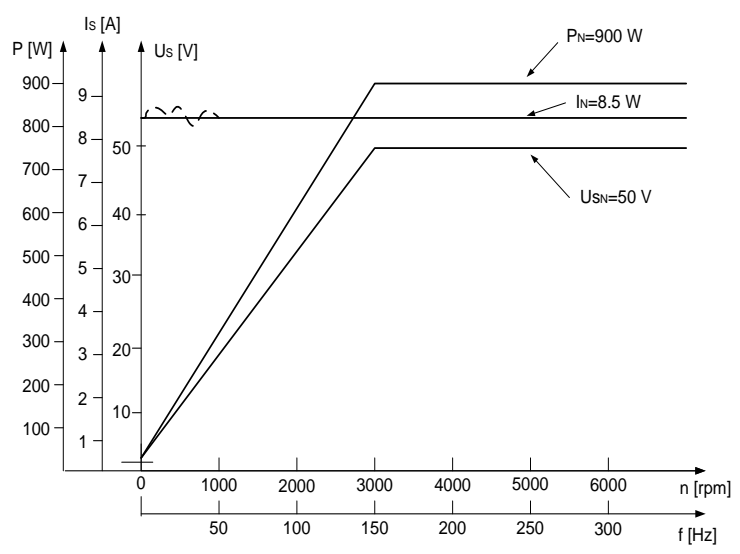

Fig.6 Experimental power, voltage and current curves of the PM motor

A good elasticity can be seen, achieving the maximum value of rotational speed $n_{\max }=5970 \mathrm{rpm}$ and the minimal value of torque $T_{\min }=C_{\min }$ $=1.25 \mathrm{Nm}$.

The ratio between the maximum and minimum values of the PM motor torque is 2.32,thisshows a good elasticity of the torque characteristic within traction conditions.

Also the ratio $n_{\max } d n_{\min }=2$ corresponds to the literature recommended values of $1.5-2[1,5]$.

\section{Conclusions}

In this paper two types of electrical motor used for electrical propulsion have been studied and analyzed.

The NX840 motor type of, has been tested on a test bench simulating a hybrid electric vehicle. For the STS 142-2/6 second type of motor analyzed, the traction curves have been obtained, reliving the behavior of the motor in traction operating modes.

From making tests on both motors, acquiring data and processing them, main curves describing electrical and mechanical parameters have been obtained.

Theoretical aspects are verified by practical tests, simulations and data processing on a testing bench in laboratory conditions.

Within this research work some master students are involved in order to develop their dissertations.

\section{References:}

[1] L. Guzzella, A. Sciaretta, Vehicle Propulsion Systems-Introduction to Modeling and Optimization,Second Edition, Springer-Verlag, 2007, ISBN 978-3-540-74691-1.

[2] M.Ehsani, K.M. Rahman, H.A. Toliyat "Propulsion System Design of Electric and Hybrid Vehicles", IEEE Trans. On Ind. Electronics, vol. 44, no. 1, pp.19-27, Feb. 1997.

[3] M. Georgescu, "Study on A.C. Electrical Transmissions with Synchronous Motors", Ph.D. Thesis, University Politehnica of Bucharest, Romania, July, 1997.

[4] M. Ehsani,, G. Yimin, S. Gay, "Characterization of electric motor drives for traction applications", Industrial Electronics Society, IECON, vol.1, pp.891-896, Nov.2003.

[5] C. Lungoci, D.Bouquain, A.Miraoui, E.Helerea, "Modular test bench for a hybrid electric vehicle with multiples energy sources ", Proc. of IEEE OPTIM Conference, Brasov, Romania, May, 2008. 